\title{
Assessment of Fault Location Techniques in Voltage Source Converter based HVDC systems
}

\author{
Tzu-Chieh Peng, Dimitrios Tzelepis, Adam Dyśko, Ivan Glesk \\ Department of Electronic \& Electrical Engineering \\ University of Strathclyde \\ Glasgow, UK
}

\begin{abstract}
This paper investigates fault location techniques in high voltage direct current (HVDC) transmission networks utilizing voltage source converters (VSCs). The subject has been extensively researched due to the fault locating actions associated with the supply restoration and the economic loss, and also because of the trending employment of VSC-HVDC transmission systems. However, the fast operation of HVDC protection has made fault localization more challenging as limited measurement data can be extracted. By broadly researching the existing fault locating approaches in such systems, a comprehensive literature review is presented. Then, two selected methods, active impedance method and travelling wave method (using Continuous Wavelet Transformation) are tested. These fault location techniques together with the power system models have been developed using Matlab/Simulink. The results are summarized and systematic comparative analysis of the two fault location techniques is performed.
\end{abstract}

Keywords - active impedance method; fault location; HVDC transmission; travelling wave; wavelet transform;

\section{INTRODUCTION}

Due to several advantages, the use of VSC-HVDC transmission systems has been increasing in recent years. This trend is accelerated by the continual development of high-power electronic devices, structures and advanced topologies, such as two-level, MMC, hybrid lines/cables and multi-terminals HVDC networks. Owing to the nature of the rapidly rising fault currents and the fault vulnerability [1], the requirements for high speed operation of protection schemes in such systems are far greater than those used in $\mathrm{AC}$ transmission networks. Accordingly, the fault location techniques used in VSC-HVDC systems can be diverse, relatively new, more crucial, more critical and not necessarily applicable in every type of topology. Given that numerous fault locating methods in such systems have been proposed and are being continually updated, the content of this paper is divided into two main parts. The first part includes the literature review on the conventional and state-ofthe-art fault location methods. The second part includes the simulation-based fault location analysis based on the two selected fault location techniques, under different fault conditions and with different types of transmission lines. The simulation-based fault location analysis is performed in stages as follows:

- System modelling: A typical point-to-point, two-level VSCHVDC system is built for simulation purposes. Single and hybrid transmission lines have been taken into account during fault analysis.
- Fault scenario generation: A series of faults taken place along the DC line are generated, including Pole-to-Pole Faults (PPFs) and Pole-to-Ground Faults (PGFs) with various ground fault resistances.

- Implementation of selected techniques: The methodologies of the selected fault locating methods are explained and then employed for fault position estimation.

- Evaluation of fault location results: The fault location results are evaluated and compared for the selected techniques. Finally, different perspectives for adaptation of each technique in practice are discussed.

\section{REVIEW OF EXISTING FAUlt LOCATION TECHNIQUES}

In conventional $\mathrm{AC}$ networks, the types of fault location techniques that have been developed over decades are many and varied. However, all of the approaches require signal measurements of voltage and/or currents despite the algorithms and principles employed being distinct from each other. Hence, even with significant variation in fault characteristics for HVDC systems, the fault location techniques used in such systems are fundamentally similar to those used in AC systems. The main fault location methods used in HVDC networks can be classified into three types: Travelling Waves (TWs), Impedance Based and Other Methods.

\section{A. Travelling Waves}

When a fault occurs in a transmission line a transient disturbance that propagates along the line at a constant speed is generated. Such disturbances are known as TWs and are present both in voltages and currents. Based on specific features of these TWs (e.g. arrival time and time difference between adjacent waves) a fault location estimation can be implemented. TW based fault locating techniques have been successfully employed for both HVAC and HVDC transmission systems [2] [3]. In fact, most of the fault localization approaches employed in HVDC systems are based on such practices due to their superior performance as well as due to the difficulty with implementation of the impedance based method (as will be discussed later). Depending on the number of measurements utilized, either one-ended or two-ended techniques can be found in the literature [4]. The principle of TW based fault location involves signal processing in order to detect the arrival of each wave and calculate its arrival time, polarity, and energy [4]. According to the specific type of signal processing used, several methods are employed including: Continuous Wavelet 
Transformation (CWT) [4] [5], Discrete Wavelet Transformation (DWT) [6], Mathematical Morphology [7], Natural Frequency Extraction [8], Empirical Mode Decomposition (EMD) [9] and Wavelet Packet Decomposition (WPD) [10]. Even though TW based fault location techniques can be of very high performance, some challenges are frequently cited as drawbacks of such methods. These include the requirement for high frequency sampling, wave detection difficulty, sensitivity to noise, and performance issues under high resistive faults [11].

\section{B. Impedance Based}

The lack of fundamental frequency components in DC systems is the main restriction in applying any impedance based fault location methods [12]. Although the natural response frequencies following the fault induced transient can be used in impedance calculation, the limited transient period makes the algorithms involved with this technique more complex in comparison with those in AC systems. Thus, the literature resources describing the use of such methods are very few indicating practical obstacles in the successful implementation of impedance based techniques in HVDC systems. Nevertheless, two related publications [13] [14] can be found where complex algorithms are used to approximate the fault loop impedance.

Another possible approach, described in some papers [15] [16], is based on using active impedance measurements. The term "active" in this context means that a fixed frequency current or voltage generator is used to inject signals into the DC line as the fundamental component. In [15], the fundamental component is generated by internal devices in the HVDC converters, while [16] uses a portable pulse generating device that carries a penalty in terms of increased installation time.

\section{Other Methods}

As a result of the challenges presented above for TW and impedance based methods, alternative approaches can also be found in the technical literature. Some utilize artificial intelligence type analysis, such as pattern recognition, to establish voltage signal similarity for different types of faults and locations [10]. Other methods utilize time reversal of specific observation points known as Electromagnetic Time Reversal (EMTR) to estimate the location of the fault [17].

\section{TeSt SYstem ModelLing}

This work assesses two existing fault location methods in VSC-HVDC systems. Two HVDC transmission test systems are utilized in the studies as depicted in Fig. 1 and Fig. 2.

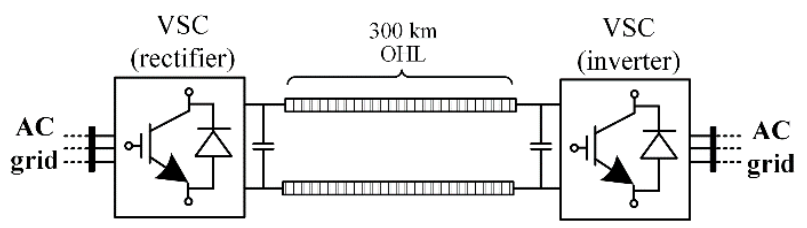

Fig. 1. Test Model 1 - Point-to-point VSC-HVDC transmission network.

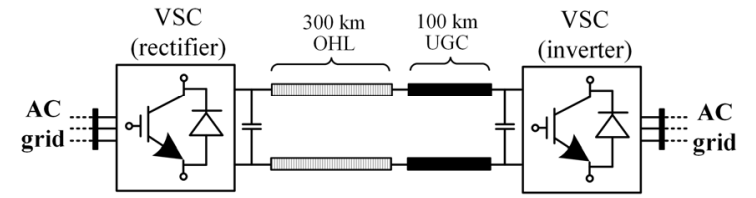

Fig. 2. Test Model 2 - Point-to-point VSC-HVDC network with hybrid transmission line.

The models have been developed in Matlab/Simulink ${ }^{\circledR}$ using the SimPowerSystems components library. Both networks are a common point-to-point $640 \mathrm{kV}( \pm 320 \mathrm{kV})$ symmetric monopole HVDC systems, with two two-level VSC converters connected to a $400 \mathrm{kV}$ AC network. The difference between the two testing models lies across the transmission medium. In Test Model 1 (TM-1) only the overhead lines (OHLs) has been considered, while the Test Model 2 (TM-2) utilizes a hybrid transmission system including both OHLs and underground cables (UGCs). Such hybrid transmission networks represent typical installations where large-scale offshore wind farms are connected to onshore grids [12]. Hence it is crucial to apply fault location techniques with hybrid transmission networks. Both OHLs and UGCs have been modelled by utilizing the distributed parameter line model as it can represent transients more accurately than lumped parameters [18]. The parameters used for the converters and the $\mathrm{AC}$ network are presented in TABLE I. while the parameters for OHL and UGC are presented in TABLE II.

\section{TABLE I. CONVERTER AND AC NETWORK PARAMETERS}

\begin{tabular}{|c|c|c|}
\cline { 2 - 3 } \multicolumn{1}{c|}{} & Parameter & Value \\
\hline \multirow{4}{*}{ Converter } & DC Voltage $\left[\mathrm{V}_{\mathrm{dc}}\right]$ & $640 \mathrm{kV}$ \\
\cline { 2 - 3 } & IGBT Turn-on resistance $\left[\mathrm{R}_{\mathrm{on}}\right]$ & $1 \mathrm{~m} \Omega$ \\
\cline { 2 - 3 } & DC-link capacitance $\left[\mathrm{C}_{\mathrm{dc}}\right]$ & $1 \mu \mathrm{F}$ \\
\hline \multirow{4}{*}{$\begin{array}{c}\text { AC } \\
\text { Network }\end{array}$} & AC voltage (Phase-to-phase, $\mathrm{RMS}$ ) & $400 \mathrm{kV}$ \\
\cline { 2 - 3 } & AC frequency & $50 \mathrm{~Hz}$ \\
\cline { 2 - 3 } & X/R Ratio of AC network & 10 \\
\cline { 2 - 3 } & 3-phase short-circuit level & $2 \mathrm{GVA}$ \\
\cline { 2 - 3 } & Interfacing transformer voltages & $400 \mathrm{kV} / 330 \mathrm{kV}$ \\
\hline
\end{tabular}

TABLE II. OHL AND UGC PARAMETERS

\begin{tabular}{|cc|c|c|}
\hline \multicolumn{2}{|c|}{ Parameter } & OHL & UGC \\
\hline DC line resistance & {$\left[\mathrm{R}_{\text {line }}\right]$} & $0.015 \Omega / \mathrm{km}$ & $0.0146 \Omega / \mathrm{km}$ \\
\hline DC line capacitance & {$\left[\mathrm{C}_{\text {line }}\right]$} & $0.012 \mu \mathrm{F} / \mathrm{km}$ & $0.275 \mu \mathrm{F} / \mathrm{km}$ \\
\hline DC line inductance & {$\left[\mathrm{L}_{\text {line }}\right]$} & $0.96 \mathrm{mH} / \mathrm{km}$ & $0.158 \mathrm{mH} / \mathrm{km}$ \\
\hline
\end{tabular}

IV. IMPEDANCE BASED METHOD

In this section an impedance based fault location method is introduced. Simulation results are presented for both PPFs and PGFs applied in the TM-1 as described in Section III. Judging from the non-ideal performance of the results applied in TM1(as shown in subsection B.), such a method may be not particle as well as in TM-2. Hence, this method will not be implemented in TM-2.

\section{Proposed Method 1}

When the active impedance method is applied, the word 'active' implies the necessity of sources injected into the line due to the absence of fundamental components in DC networks. Assuming that the DC converters are detached after the fault, a 
portable single-phase AC voltage source is connected at the end of one line (e.g. rectifier end). The illustration of the equipment installation in the testing models is shown in Fig. 3. Compared to fault locating techniques used in the HVAC networks, the utilization of a 500 volts, $50 \mathrm{~Hz}$, single-phase source makes the method simpler as it is spared from considering the symmetrical components [3]. The terminal measurements (i.e. voltages and currents) recorded during the $\mathrm{AC}$ source operation are used to compute the apparent impedance between the terminal and the position of the short-circuit fault. This apparent impedance is then applied to proceed further algorithms, which might differ from the fault current loops [19].

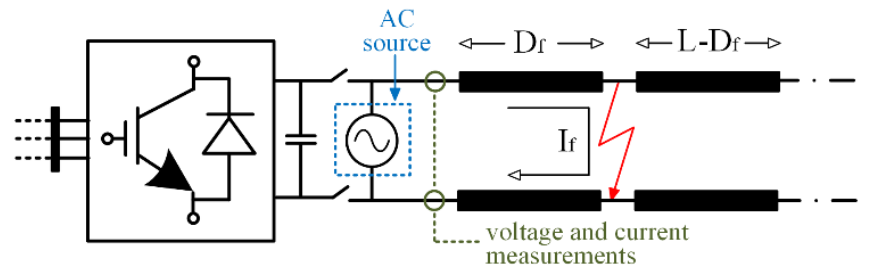

Fig. 3. Representation of impedance-based fault location method setup.

A current $\boldsymbol{I}_{\boldsymbol{f}}$ generated from the mounted AC source flows into the loop which has formed due to the fault. This scenario assumes a fault occurs at the equal position between two poles, and that the line is a simple model which consists of only resistance and inductance. The total line impedance and the apparent impedance can be straightforwardly obtained with the known parameters and the phasor measurements.

$$
\begin{gathered}
Z_{\text {line }}=\left[R_{\text {line }}+j \omega L_{\text {line }}\right] \\
\mathrm{Z}_{\mathrm{app}}=\frac{\mathrm{v}}{\mathrm{I}_{\mathrm{f}}}
\end{gathered}
$$

where $Z_{\text {line }}$ is the line impedance per unit length, $\omega$ the angular frequency, $Z_{\text {app }}$ the apparent impedance of the fault loop, $V$ the pole-to-pole phasor voltage and $I_{f}$ the fault loop current.

Depending on the type of fault, different voltage measurements have been utilized. Specifically, for both PPF and PGF, pole-to-pole and pole-to-ground voltages have been used respectively. The fault position $D_{f}$ can then be estimated by the proportion of the imaginary part of the apparent impedance and twice the imaginary part of the total line impedance [3]:

$$
\mathbf{D}_{\mathbf{f}}=\frac{\mathfrak{I}\left(\mathbf{Z}_{\text {app }}\right)}{2 \times \mathfrak{J}\left(\mathbf{Z}_{\text {line }}\right)}
$$

Note that the equation which takes only the imaginary part is the so-called simple reactance method. Theoretically, the aim of this implementation is to eliminate the possible error caused by fault resistance as the fault is resistive in nature [19]. However, the effectiveness of the elimination may be debatable judging from the results shown later on.

\section{E. Simulation Results}

In this section simulation results are presented for the impedance based fault location method as described in the previous subsection. Fault location results include the cases of PPFs but also PGFs across the transmission line of TM-1. Fault location results for metallic PPFs are illustrated in TABLE III. It can be seen from the results that the impedance based fault location method can accurately locate the distance to the fault. However, a trend can be observed in the error which increases proportionally with the fault distance. In the case of PGFs, when low-resistive ground faults are introduced, the impedance method has a similar performance (not shown due to space limitations). However, with the increase of the fault resistance, it can be seen that there were significant errors in the results. In TABLE IV. , it can be observed that over $75 \Omega$ the mean error increases significantly to an almost unacceptable level. It is therefore clear at this point that the impedance based fault location method might not be suitable for accurate fault location in VSC-HVDC networks since the accuracy is severely affected by the ground fault resistance. The resulting errors could be caused by neglecting the parallel capacitances on the transmission line. In [15], an iterative compensation algorithm has been employed successfully in a relatively simple PI model, where the impedance is easier to calculate compared to the distributed parameter model. Nevertheless, distributed transmission line models are designed to approximate the situation in reality, especially for a long transmission line. It may be more reasonable and valuable to adopt such line models when simulating and verifying a method.

\begin{tabular}{|c|c|c|c|c|c|c|}
\hline Fault Pos. [km] & 10 & 50 & 110 & 190 & 250 & 290 \\
\hline Calc. Pos. [km] & 10.00 & 50.05 & 110.51 & 192.64 & 256.07 & 299.59 \\
\hline $\begin{array}{ll}\text { Error } & {[\mathrm{km}]}\end{array}$ & 0.000 & 0.047 & 0.506 & 2.636 & 6.079 & 9.586 \\
\hline Error & 0.012 & 0.016 & 0.169 & 0.879 & 2.026 & 3.195 \\
\hline
\end{tabular}

TABLE III. FAULT LOCATION RESULTS FOR ACTIVE IMPEDANCE METHOD AND FOR PPF

TABLE IV. RESUlTING MEAN ERRORS ACTIVE IMPEDANCE METHOD FOR PGFS AND FOR DIFFERENT FAULT RESISTANCES

\begin{tabular}{|l|c|c|c|c|c|c|c|c|}
\hline Fault Res. [ $\mathbf{\Omega}]$ & $\mathbf{2 5}$ & $\mathbf{5 0}$ & $\mathbf{1 0 0}$ & $\mathbf{1 2 5}$ & $\mathbf{1 5 0}$ & $\mathbf{1 7 5}$ & $\mathbf{2 0 0}$ & $\mathbf{2 5 0}$ \\
\hline Mean Err. [\%] & 1 & 2 & 12 & 20 & 28 & 38 & 49 & 75 \\
\hline
\end{tabular}

\section{Travelling Wave Based Method}

In this section, a TW based fault location method is introduced. Simulation results are presented for employing both the one-ended and two-ended methods to calculate the fault location when PPGs and PGFs happen in TM-1. In addition, a two-ended algorithm for a hybrid transmission as proposed in [4] will be tested in TM-2.

\section{F. Proposed Method 2}

The TW based method determines the fault distance by calculating the time period between two reaching surges, using either the one- or two-ended method. Thus, the wave-front arrival time must be precisely identified to achieve a high accuracy in estimation. There are numerous edge detecting techniques such as the Wavelet Transformation (WT), Short Time Fourier Transform (STFT) and Finite Impulse Response 
(FIR) filtering based methods [3]. However, WT is the one which has been widely implemented in recent research for locating faults in HVDC systems [5], due to the capability of frequency localization and analyzing in the time scale region.

Despite the common adaption of DWT in HVDC fault location and protection schemes, the CWT provides superior time resolution and gives enhanced accuracy [5]. Consequently, in the proposed TW method using the CWT approach is adopted.

The WT of a function $f(t)$ is the integral of the product between $f(t)$ and a scaled and shifted version of the mother wavelet (MW) $\psi(t)[3]$ :

$$
\operatorname{CWT}(f(t) ; p, \tau)=\int_{-\infty}^{\infty} f(t) \psi_{(p, t)}^{*}(t) d t
$$

The scaling and the shifting of the mother wavelet $\psi(t)$ is implemented by the scale factor (SF) $p$ and the time shift $\tau[3]$ :

$$
\psi_{(p, t)}^{*}(t)=\frac{1}{\sqrt{p}} \psi\left(\frac{t-\tau}{p}\right)
$$

where * represents the complex conjugate.

After the CWT has been applied and the arrival times of the waves have been identified the fault location $D_{f}$ has to be calculated. This is achieved by using equation 5 and 6 for oneand two-ended method respectively [3]:

$$
\begin{gathered}
D_{f}=\frac{t_{R 2}-t_{R 1}}{2} \\
D_{f}=\frac{\left[L-\left(\Delta t_{A, B}\right) v\right]}{2}
\end{gathered}
$$

where $t_{R 2}-t_{R 1}$ is the time time difference between two consecutive waves (at the same terminal), $v$ is the propagation speed, $L$ is the total length of the line and $\Delta t_{A, B}$ is the time difference of the first waves (from the measurements at different terminals).

When the TM-2 has been used, by solving the TW equations, the fault location $D_{f}$ can be calculated from equation 8 when the fault is in the OHL, and from equation (9), when the fault is within the UGC.

$$
\begin{gathered}
D_{f(O H L)}=\left(\left|T_{R 1}-T_{I 1}\right|+\frac{L_{O H L}}{v_{O H L}}+\frac{L_{U G C}}{v_{U G C}}\right) \times \frac{v_{O H L}}{2} \\
D_{f(U G C)}=L_{O H L}+\left(\left|T_{R 1}-T_{I 1}\right|-\frac{L_{O H L}}{v_{O H L}}+\frac{L_{U G C}}{v_{U G C}}\right) \times \frac{v_{U G C}}{2}
\end{gathered}
$$

where $T_{R 1}$ and $T_{I 1}$ are the first surge arrival time from both terminals, $v_{O H L}$ and $v_{U G C}$ are the wave propagation speed of OHL and UGC respectively, $L_{O H L}$ and $L_{U G C}$ represent the length of line and cables accordingly.

It is worth noting here some research has focused on the fault location techniques in segmented HVDC systems. In [6], the Support Vector Machine (SVM) has been used to distinguish which of the segments is being faulted, then the location can be decided using one-ended TW method with DWT. Alternatively, [4] employed the two-ended, TW based method using CWT, then the fault distance could be calculated by the developed algorithm with the known propagation speed of each segment. The latter methodology is applied in equations (8) and (9) as it is straightforward and the requirement of SVM is completely eliminated.

\section{G. Methodology and Testing Conditions}

For the proposed method, current and voltage measurements are recorded prior and during the faults at a sampling time of $3 \mu \mathrm{s}$. Prior to the CWT the derivative of the DC current $\mathrm{dI}_{\mathrm{dc}} / \mathrm{dt}$ has been calculated, in order to "sharpen" the edges of the input signal (act as a high-pass filter) making the waves easily detectable. The arrival time of the waves are then determined by comparing the signal with a predefined fixed threshold value, which is typically set from $1 \%$ to $20 \%$ of the maximum magnitude of the first signal [20]. In Fig. 4 an example of the CWT conversion is illustrated for a metallic PPF at TM-1 at 100 $\mathrm{km}$ from the rectifier end. The CWT has been performed by using MW 'haar' with a SF of 2. For the calculation of the arrival times of TWs, the threshold comparison has been set to $15 \%$ of the first spike. Several fault scenarios are simulated, and the data are processed by CWT with various selection of MW and SFs.
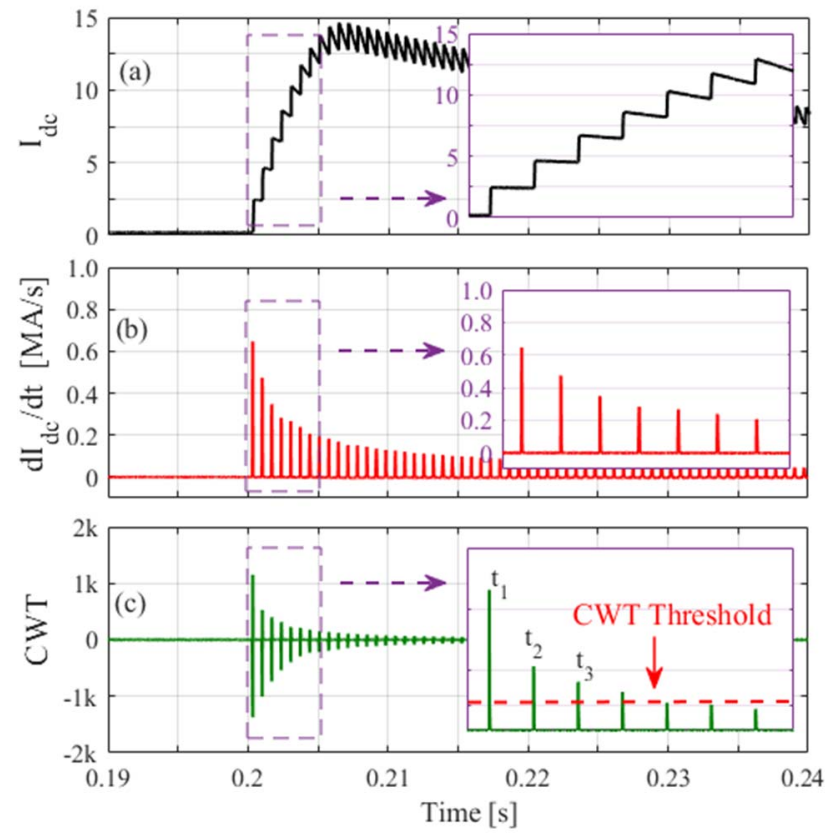

Fig. 4. PPF at $100 \mathrm{~km}(\mathrm{TM}-1)$. a) DC current $\mathrm{I}_{\mathrm{dc}}$, b) Rate of change of DC current $\mathrm{dI}_{\mathrm{dc}} / \mathrm{dt}$. CWT of $\mathrm{dI} \mathrm{d}_{\mathrm{dc}} / \mathrm{dt}$.

\section{H. Simulation Results}

In this subsection comparative and summarized results of the CWT based TW approach are presented in for the TM-1 and TM-2 both for PPFs and PGFs.

The outcomes of inputting the data from either end behaves similarly when employing the one-ended method. In addition, the results when introducing various resistive PGFs, ranging 
from $25 \Omega$ to $500 \Omega$, also show high similarity. For the sake of simplicity, the results of a $50 \Omega$ ground fault resistance are displayed as a representative example. TABLE V. and TABLE VI. present cases of metallic PPFs faults and PGFs respectively, (both for TM-1) in various fault locations with different MW and SFs. As both tables show, CWT with MW 'haar' give accurate fault location estimation with various SFs, whereas MW 'db3' operate ideally only with specific SFs or fault positions. As the failed cases indicate, the inappropriate selection of MW and SFs of the TWs can crucially affect the accuracy.

TABLE V. ONE-ENDED CWT BASED FAULT LOCATION RESULTS FOR METALIC PPFS AT TM-1.

\begin{tabular}{|c|c|c|c|c|c|c|c|}
\hline \multirow{3}{*}{ MW } & Error & $\begin{array}{l}\text { Err. } \\
{[\mathbf{k m}]}\end{array}$ & $\begin{array}{l}\text { Err. } \\
{[\%]}\end{array}$ & $\begin{array}{l}\text { Err. } \\
{[\mathrm{km}]}\end{array}$ & $\begin{array}{l}\text { Err. } \\
{[\%]}\end{array}$ & $\begin{array}{l}\text { Err. } \\
{[\mathbf{k m}]}\end{array}$ & $\begin{array}{l}\text { Err. } \\
{[\%]}\end{array}$ \\
\hline & $\mathrm{SF} \rightarrow$ & \multirow{2}{*}{\multicolumn{2}{|c|}{1}} & \multirow{2}{*}{\multicolumn{2}{|c|}{4}} & \multirow{2}{*}{\multicolumn{2}{|c|}{16}} \\
\hline & $\begin{array}{l}\text { Fault Pos. } \\
{[\mathrm{km}] \downarrow}\end{array}$ & & & & & & \\
\hline \multirow{7}{*}{ haar } & 10 & 0.09 & 0.03 & 0.09 & 0.03 & 0.09 & 0.03 \\
\hline & 50 & 0.14 & 0.05 & 0.14 & 0.05 & 0.14 & 0.05 \\
\hline & 110 & 0.03 & 0.01 & 0.03 & 0.01 & 0.03 & 0.01 \\
\hline & 190 & 0.40 & 0.13 & 0.40 & 0.13 & 0.40 & 0.13 \\
\hline & 250 & 0.50 & 0.17 & 0.06 & 0.02 & 0.06 & 0.02 \\
\hline & 290 & 0.28 & 0.09 & 0.28 & 0.09 & 0.28 & 0.09 \\
\hline & Mean & 0.24 & 0.08 & 0.17 & 0.06 & 0.17 & 0.06 \\
\hline \multirow{7}{*}{ db3 } & 10 & 10.09 & 0.03 & 0.09 & 0.03 & 0.09 & 0.03 \\
\hline & 50 & 249.12 & 83.04 & 0.14 & 0.05 & 0.14 & 0.05 \\
\hline & 110 & 189.12 & 63.04 & 0.03 & 0.01 & 0.03 & 0.01 \\
\hline & 190 & 108.67 & 36.22 & 0.04 & 0.01 & 0.04 & 0.01 \\
\hline & 250 & 48.67 & 16.22 & 0.38 & 0.13 & 0.06 & 0.02 \\
\hline & 290 & 0.28 & 0.09 & 0.16 & 0.05 & 0.16 & 0.05 \\
\hline & Mean & 100.99 & 33.11 & 0.14 & 0.05 & 0.09 & 0.03 \\
\hline
\end{tabular}

TABLE VI. ONE-ENDED CWT BASED FAULT LOCATION RESULTS FOR PGFS AT TM-1 WITH GROUD RESISTANCE OF $50 \Omega$

\begin{tabular}{|c|c|c|c|c|c|c|c|}
\hline \multirow{3}{*}{ MW } & Error & $\begin{array}{l}\text { Err. } \\
{[\mathrm{km}]}\end{array}$ & $\begin{array}{l}\text { Err. } \\
{[\%]}\end{array}$ & $\begin{array}{l}\text { Err. } \\
{[\mathrm{km}]}\end{array}$ & $\begin{array}{l}\text { Err. } \\
{[\%]}\end{array}$ & $\begin{array}{l}\text { Err. } \\
{[\mathrm{km}]}\end{array}$ & $\begin{array}{l}\text { Err. } \\
{[\%]}\end{array}$ \\
\hline & SF $\rightarrow$ & \multirow{2}{*}{\multicolumn{2}{|c|}{1}} & \multirow{2}{*}{\multicolumn{2}{|c|}{4}} & \multirow{2}{*}{\multicolumn{2}{|c|}{16}} \\
\hline & $\begin{array}{c}\text { Fault Pos. } \\
{[\mathbf{k m}] \downarrow}\end{array}$ & & & & & & \\
\hline \multirow{7}{*}{ haar } & 10 & 0.61 & 0.20 & 1.05 & 0.35 & 3.70 & 1.23 \\
\hline & 50 & 0.82 & 0.27 & 1.27 & 0.42 & 3.92 & 1.31 \\
\hline & 110 & 0.49 & 0.16 & 0.93 & 0.31 & 3.58 & 1.19 \\
\hline & 190 & 0.48 & 0.16 & 0.92 & 0.31 & 3.57 & 1.19 \\
\hline & 250 & 1.02 & 0.34 & 1.02 & 0.34 & 3.67 & 1.22 \\
\hline & 290 & 0.36 & 0.12 & 1.24 & 0.41 & 3.89 & 1.30 \\
\hline & Mean & 0.63 & 0.21 & 1.07 & 0.36 & 3.72 & 1.24 \\
\hline \multirow{7}{*}{$\mathrm{db3}$} & 10 & 0.28 & 0.09 & 0.28 & 0.09 & 4.25 & 1.42 \\
\hline & 50 & 49.12 & 16.37 & 0.06 & 0.02 & 44.25 & 14.75 \\
\hline & 110 & 109.12 & 36.37 & 0.04 & 0.01 & 104.25 & 34.75 \\
\hline & 190 & 188.67 & 62.89 & 0.03 & 0.01 & 0.03 & 0.01 \\
\hline & 250 & 248.67 & 82.89 & 0.14 & 0.05 & 0.14 & 0.05 \\
\hline & 290 & 0.09 & 0.03 & 0.09 & 0.03 & 284.25 & 94.75 \\
\hline & Mean & 99.32 & 33.11 & 0.11 & 0.04 & 72.87 & 24.29 \\
\hline
\end{tabular}

The performance using the two-ended method has a similar pattern to the one-ended method, but as expected the accuracy is increased even more both for PPFs and PGFs. The fault location results utilizing the two-ended method, for PPFs and PGFs applied at TM-1, are presented in TABLE VII. and TABLE VIII. respectively; As the tables show, CWT with the selection of MW 'haar' gives the best results with the error being reduced to less than $0.1 \%$.

In TABLE IX. , the fault location results for PPFs and PGFs at TM-2 are presented. The results are generated utilizing the two-ended method, MW 'haar' and SF of 2. Additionally, the PPFs were considered metallic (fault resistance $0.001 \Omega$ ) while for PGFs the ground fault resistance was $500 \Omega$.

With the outcomes shown in TABLE IX., it is therefore proved that the proposed approach can successfully estimate fault location in both types of faults and their positions regardless of the faulted segment (i.e. OHL, UGC or joint between them). It is worth stating at this stage that the TW (with the utilization of CWT) can be successfully applied to multisegmented transmission lines.

TABLE VII. TWD-ENDED CWT BASED FAULT LOCATION RESULTS FOR METALIC PPFS AT TM-1.

\begin{tabular}{|c|c|c|c|c|c|c|}
\hline Error & $\begin{array}{l}\text { Err. } \\
{[\mathbf{k m}]}\end{array}$ & $\begin{array}{l}\text { Err. } \\
{[\%]}\end{array}$ & $\begin{array}{l}\text { Err. } \\
{[\mathbf{k m}]}\end{array}$ & $\begin{array}{l}\text { Err. } \\
{[\%]}\end{array}$ & $\underset{[\mathbf{k m}]}{\text { Err. }}$ & $\begin{array}{l}\text { Err. } \\
{[\%]}\end{array}$ \\
\hline $\mathbf{S F} \rightarrow$ & \multirow{2}{*}{\multicolumn{2}{|c|}{1}} & \multirow{2}{*}{\multicolumn{2}{|c|}{4}} & \multirow{2}{*}{\multicolumn{2}{|c|}{16}} \\
\hline $\begin{array}{c}\text { Fault Pos. } \\
{[\mathrm{km}] \downarrow}\end{array}$ & & & & & & \\
\hline 10 & 0.10 & 0.03 & 0.10 & 0.03 & 0.10 & 0.03 \\
\hline 50 & 0.12 & 0.04 & 0.12 & 0.04 & 0.12 & 0.04 \\
\hline 110 & 0.22 & 0.07 & 0.23 & 0.08 & 0.23 & 0.08 \\
\hline 190 & 0.22 & 0.07 & 0.23 & 0.08 & 0.23 & 0.08 \\
\hline 250 & 0.12 & 0.04 & 0.12 & 0.04 & 0.12 & 0.04 \\
\hline 290 & 0.10 & 0.03 & 0.10 & 0.03 & 0.10 & 0.03 \\
\hline Mean & 0.14 & 0.05 & 0.15 & 0.05 & 0.15 & 0.05 \\
\hline
\end{tabular}

TABLE VIII. TWO-ENDED CWT BASED FAULT LOCATION RESULTS FOR PGFS AT TM- 1 WITH GROUD RESISTANCE OF $50 \Omega$.

\begin{tabular}{|c|c|c|c|c|c|c|}
\hline Error & $\begin{array}{l}\text { Err. } \\
\text { [km] }\end{array}$ & $\begin{array}{l}\text { Err. } \\
{[\%]}\end{array}$ & $\begin{array}{l}\text { Err. } \\
{[\mathbf{k m}]}\end{array}$ & $\begin{array}{l}\text { Err. } \\
{[\%]}\end{array}$ & $\begin{array}{l}\text { Err. } \\
{[\mathbf{k m}]}\end{array}$ & $\begin{array}{l}\text { Err. } \\
{[\%]}\end{array}$ \\
\hline $\mathbf{S F} \rightarrow$ & \multirow{2}{*}{\multicolumn{2}{|c|}{1}} & \multirow{2}{*}{\multicolumn{2}{|c|}{4}} & \multirow{2}{*}{\multicolumn{2}{|c|}{16}} \\
\hline $\begin{array}{c}\text { Fault Pos. } \\
{[\mathbf{k m}] \downarrow}\end{array}$ & & & & & & \\
\hline 10 & 0.10 & 0.03 & 0.10 & 0.03 & 0.10 & 0.03 \\
\hline 50 & 0.12 & 0.04 & 0.12 & 0.04 & 0.12 & 0.04 \\
\hline 110 & 0.22 & 0.07 & 0.23 & 0.08 & 0.23 & 0.08 \\
\hline 190 & 0.22 & 0.07 & 0.23 & 0.08 & 0.23 & 0.08 \\
\hline 250 & 0.12 & 0.04 & 0.12 & 0.04 & 0.12 & 0.04 \\
\hline 290 & 0.10 & 0.03 & 0.10 & 0.03 & 0.10 & 0.03 \\
\hline Mean & 0.14 & 0.05 & 0.15 & 0.05 & 0.15 & 0.05 \\
\hline
\end{tabular}

TABLE IX. TWO-ENDED CWT BASED FAULT LOCATION RESULTS FOR PPFS AND PGFS AT TM-2.

\begin{tabular}{|c|c|c|c|c|c|c|c|c|}
\hline \multicolumn{2}{|c|}{ Fault Pos. [km] } & 10 & 30 & 50 & 110 & 130 & 150 & \multirow{6}{*}{ OHL } \\
\hline \multirow{2}{*}{$\begin{array}{c}\text { Error } \\
(\%)\end{array}$} & $\mathbf{P P}$ & 0.05 & 0.03 & 0.02 & 0.03 & 0.06 & 0.02 & \\
\hline & PG & 0.05 & 0.03 & 0.02 & 0.03 & 0.06 & 0.02 & \\
\hline \multicolumn{2}{|c|}{ Fault Pos. $[\mathrm{km}]$} & 170 & 190 & 210 & 250 & 270 & 300 & \\
\hline \multirow{2}{*}{$\begin{array}{c}\text { Error } \\
(\%)\end{array}$} & PP & 0.06 & 0.00 & 0.06 & 0.02 & 0.07 & 0.05 & \\
\hline & PG & 0.06 & 0.00 & 0.06 & 0.02 & 0.08 & 0.05 & \\
\hline \multicolumn{2}{|c|}{ Fault Pos. $[\mathrm{km}]$} & 310 & 330 & 350 & 370 & 380 & 390 & \multirow{3}{*}{ UGC } \\
\hline \multirow{2}{*}{$\begin{array}{c}\text { Error } \\
(\%)\end{array}$} & PP & 0.03 & 0.03 & 0.04 & 0.05 & 0.05 & 0.07 & \\
\hline & PG & $\overline{0.03}$ & 0.03 & 0.04 & 0.05 & 0.05 & 0.08 & \\
\hline
\end{tabular}




\section{RESUlts SUMMARY AND DiSCUSSION}

In comparison with the requirements of protection schemes in VSC-HVDC networks, fault location is less time-critical, and is more focused on accuracy. From this point of view, the simulation results, in addition to their poor performance under resistive ground fault conditions indicate that the active impedance method is not as reliable in locating the faults in VSC-HVDC systems. In contrast, the TW based methods using CWT are capable of accurately estimating the fault position for various fault scenarios occurring at different locations. They are also applicable to hybrid systems where a two-ended method is applied. In addition to accuracy, there are also other aspects which need to be considered when committing to choice of fault locating techniques implementation. The advantages and disadvantages regarding different perspectives of the two approaches can be summarised as follows:

\section{- Active Impedance Method}

This method is relatively simple computationally and requires no high sampling frequency equipment. However, with the error approaching $3 \%$ for non-resistive faults and up to 70 $\%$ for high resistive ground faults, such a method is not practical even in a single line system. Although by additional compensation, the algorithm could possibly improve the accuracy, such fault location techniques can still be non-ideal for consideration since the unavoidable demand of an AC source increases the system downtime.

\section{- TW Method Using CWT}

The simulation results have shown that TW based methods can locate faults with an error of less than $0.1 \%$. In addition, TW based methods are robust to highly resistive PGFs and can be adapted for use in hybrid line/cables (two-ended method with the proposed algorithm). Such techniques require complex data processing, and perform well on the condition with the appropriate choice of MW and SFs, and precise wave-front detection when using the one-ended method. Additionally, high frequency sampling is needed to precisely extract the features of interest from the waveforms, as the wave propagation speed is near to speed of light. The two-ended method gives the best performance, but the unsynchronized time-domain measurement from two terminals could lead to additional errors. Hence, the demand of GPS communication or synchronized measurements could be an important factor in utilizing such techniques [14].

\section{CONCLUSION}

In this paper, fault location techniques in VSC-HVDC transmission networks have been described and assessed using computer-based simulation. According to the results, fault location using the TW based method with CWT shows a superior performance, while the active impedance method is considerably less promising when employed in HVDC systems. While fault location techniques have been developed over decades, the growth in complexity and the increasing variety of transmission network applications requires the development of new, reliable and practical approaches.

\section{REFERENCES}

[1] D. Tzelepis, S. Ademi, D. Vozikis, A. Dysko, S. Subramanian and H. Ha, "Impact of VSC converter topology on fault characteristics in HVDC transmission systems," in 8th IET International Conference on Power Electronics, Machines and Drives, Glasgow, 2016, pp. 1-6.

[2] E. O. Schweitzer, A. Guzmán, M. V. Mynam, V. Skendzic, B. Kasztenny and S. Marx, "Locating faults by the traveling waves they launch," in 67th Annual Conference for Protective Relay Engineers, College Station, TX, 2014, pp. 95-110.

[3] M. M. Saha, J. Izykowski and E. Rosolowski, Fault location on power networks, London: Springer, 2010.

[4] O. K. Nanayakkara, A. D. Rajapakse and R. Wachal, "Location of DC line faults in conventional hvdc systems with segments of cables and overhead lines using terminal measurements," IEEE Trans. Power Del., vol. 27, pp. 279-288, Jan. 2012.

[5] O. K. Nanayakkara, A. D. Rajapakse and R. Wachal, "Fault location in extra long HVDC transmission lines using continuous wavelet transform," in International Conference on Power Systems Transients, Deft, Netherland, 2011. pp.1-7.

[6] H. Livani and C. Y. Evrenosoglu, "A single-ended fault location method for segmented HVDC transmission line," Electric Power Syst. Research, vol. 107, pp. 190-198, Feb. 2014.

[7] J. P. Triveno, V. P. Dardengo and M. C. d. Almeida, "An approach to fault location in HVDC lines using mathematical morphology," in IEEE Power \& Energy Society General Meeting, Denver, 2015.

[8] G. Song, X. Chu, X. Cai, S. Gao and M. Ran, "A fault-location method for VSC-HVDC transmission lines based on natural frequency of current," Int. J. Elect. Power \& Energy Syst., vol. 63, pp. 347-352, Dec. 2014.

[9] Z. Y. He, K. Liao, X. P. Li, S. Lin, J. w. Yang and R. K. Mai, "natural frequency-based line fault location in HVDC lines," IEEE Trans. Power Del., vol. 29, pp. 851-859, Apr. 2014.

[10] H. C. Tu and Niannian, "HVDC transmission line fault localization base on RBF neural network with wavelet packet decomposition," in 12th International Conference on Service Systems and Service Management ,Guangzhou, 2015, pp.1-4.

[11] W. Mao, S. Q. Yang, Zhang, F. Gao, Y. Song and M. Yang, "Literature review of fault location research for HVDC transmission lines," in International Power, Electronics and Materials Engineering Conference, Dalian, 2015, pp. 1-4.

[12] J. Yang, J. E. Fletcher and J. O'Reilly, "Short-circuit and ground fault analyses and location in VSC-based DC network cables," IEEE Trans. Ind. Electron, vol. 59, pp. 3827-3837, Oct. 2012.

[13] J. Suonan, S. Gao, G. Song, Z. Jiao and X. Kang, “A novel fault-location method for HVDC transmission lines," IEEE Trans. Power Del., vol. 25, pp. 1203-1209, Apr. 2010.

[14] L. de Andrade, "Time-domain impedance-based fault location for HVDC trans-mission lines," Ph.D. dissertation, Dept. Elect. and Comput Eng., Porto Univ., Porto, Portuguese, 2013

[15] M. Shukr, D. W. P. Thomas and P. Zanchetta, "VSC HVDC transmission line faults location using active line impedance estimation," in IEEE International Energy Conference and Exhibition, Florence, 2012, pp. 15.

[16] E. Christopher, M. Sumner, D. Thomas, X. Wang and F. d. Wildt, "Fault location in a zonal DC marine power system using active impedance estimation,” IEEE Trans. Ind. Appl., vol. 49, pp. 860-865, Apr. 2013.

[17] H. C. Tu and Niannian, "HVDC transmission line fault localization base on RBF neural network with wavelet packet decomposition," in 12th International Conference on Service Systems and Service Management, Guangzhou, 2015.

[18] F. C. Bucher MK, "Analysis of transient fault currents in multi-terminal HVDC networks during pole-to-ground faults," in International Conference on Power Systems Transients, Vancouver, Canada, 2013. pp. 1-7.

[19] S. Das, S. Santoso, A. Gaikwad and M. Patel, "Impedance-based fault location in transmission networks: theory and application," in IEEE Access, vol. 2, pp. 537-557, 2014.

[20] A. Elhaffar and M. Lehtonen, "Multi-End Traveling Wave Fault Location Based on Current Traveling Waves," 16th Power Systems Computation Conference, Glasgow, Scotland, 2008. pp. 1-7. 